\title{
The Reconstruction of the Anterior Cruciate Ligament on the Background of Knee Osteoarthritis
}

\author{
Golovakha $\mathrm{ML}^{1 *}$, Orljanski $\mathrm{W}^{2}$ and Benedetto $\mathrm{KP}^{3}$ \\ ${ }^{1}$ Department of Orthopaedic Surgery, Zaporozhye State Medical University, Ukraine \\ ${ }^{2}$ Department of Orthopedic Surgery, Vienna Private Clinic, Austria \\ ${ }^{3}$ Privatklinik Hochrum, Sanatorium der Kreuzschwestern GmbH A-6063 Rum, Austria
}

Submission: June 18, 2019; Published: July 03 , 2019

*Corresponding author: Golovakha ML, Department of Orthopaedic Surgery, Zaporozhye State Medical University, Mayakovskyi avenue 26, Zaporozhye, Ukraine

\section{Introduction}

Instability of the knee joint due to the injury of the anterior cruciate ligament is the issue which constantly draws attention of orthopedists. There is a constant development of methods of the reconstruction of the anterior cruciate ligament which, in its turn, primarily connected with a more accurate positioning of the graft attachment. There is a polemic in progress dedicated to the choice of the graft for the reconstruction of the anterior cruciate ligament and the ways of its attachment [1-5]. However, the instability backsets occur in 5-25\% of the cases and the level of patients returning to sport after the plastic reconstruction of the anterior cruciate ligament is from 60 to $80 \%$ [1-8] There is a special group which consists of the patients with the injury of the anterior cruciate ligament who have cartilage lesion or ongoing osteoarthritis of the knee. The results of the treatment of these patients are poor, since in most cases they are recommended to follow the conservative treatment. On the other hand, there is no clear guidance of how to proceed in such cases. A purely mechanistic approach - the reconstruction of each damaged cruciate ligament is not always justified, since the operation in the presence of osteoarthritis contributes to its progression. The aim of this work was to develop a technique of differential selection of indications for surgical treatment of the anterior instability of the knee with osteoarthritis.

\section{Objectives of the Work}

i. To examine own long-term outcomes of the patients with osteoarthritis with chronic damage to the anterior cruciate ligament.

ii. To identify the features of the destruction of the articular cartilage of the knee joint with damaged anterior cruciate ligament.

iii. To formulate the indications for the reconstruction of the anterior cruciate ligament with osteoarthrosis of the knee joint.

\section{Materials and Methods}

The conducted study was based on the analysis of the remote results of 149 patients with osteoarthritis of the knee, which were operated from 2 to 12 years ago. The age of the patients was from 36 to 63 years. Men - 86, women - 63 .

\section{Inclusion criteria}

a) Osteoarthritis of the knee joint of the I-II stages by Kellgren-Lawrence Grading Scale.

b) Traumatic injuries to the anterior cruciate ligament not older than 2 years.

c) Body mass index 30 .

d) The absence of long term synovitis, subchondral lesions of the bone edema on MRI, osteoporosis, nicotine addiction more than 2 packs of cigarettes a day.

e) Radiography or MRI at the follow-up in the long term.

All the patients had the reconstruction of the anterior cruciate ligament performed using autografts of semitendinosus and tender muscles' hamstrings that were fixed with interfering screws and "endo-buttons". Corrective osteotomy was performed at the opening procedure with osteosynthesis plates with angular stability screws. Wedge-shaped defect bone grafting was performed during the opening of more than $10 \mathrm{~mm}$. Indications for corrective osteotomy considered articular cartilage damage of the medial space (part) of the knee joint on the background of constitutional varus deformity. Cartilage condition was evaluated on the basis of MRI and confirmed during arthroscopy. Assessment of varus deformity was performed by the frontal $\mathrm{X}$-ray of the knee joint when standing and medial tibial angle was measured. At its value less than $86^{\circ}$ high corrective osteotomy of the tibia was performed. The change of tibial plateau leveling was performed with the values of more than $10^{\circ}$ and less than $3^{\circ}$. 
Postoperative treatment after the anterior cruciate ligament reconstruction was performed using the standard technique. When performing simultaneous corrective osteotomy, contrast concerned the period of the limb support. Patients walked on crutches with dosed weight bearing for 6 weeks, then another 6 weeks with a cane, then without additional support. In general, the treatment selection was not always the same as patients were operated during a long period from 2002 to 2010. There was a substantial lack of generally accepted recommendations for the choice of the treatment and adequate proper experience at the beginning.

\section{Assessment of the State of the Joint was Performed on the Basis of the following Characteristics}

i. The stage of osteoarthritis by Kellgren-Lawrence Grading Scale.

ii. The medial tibial angle.

iii. The angle of the posterior tibial plateau - "Tibial Slope".

iv. The size and the grade of cartilage damage by Outer bridge.

v. The degree of joint space narrowing based on the methods of the Osteoarthritis Research Society International [143].

Due to this procedure there are three grades of the joint space narrowing. 0 grade - normal state, I grade - narrowing to $1 / 2$ of the height, II grade - narrowing more than $1 / 2$ of the height, III grade - bone touches the bone.

The analysis of the long-term results was performed in two ways: evaluation of the knee stability and signs of progression of gonarthrosis. To assess the impact of the primary parameters the correlation between them, I.K.D.C. scale and Lequesne index was made, which were used for the assessment of the long-term results.

\section{Results}

The age of the patients in this subgroup was from 36 to 63 years (50.8 years on average). Men - 86 women - 63. Analysis showed that most of the patients $(72.5 \%)$ were under the age of 55 years (Table 1). In this case the specific weight of the other age groups was almost identical except for the group over 60 years $(4.0 \%)$. There were more patients in the age group from 36 to 49 years (40.9\%). All this testifies to the homogeneity of the sample demographics. Among 149 patients, 4 subgroups were formed due to the types of surgical interference (Table

Table 1: Age differentiation of the examined patients.

\begin{tabular}{|c|c|c|c|c|c|c|}
\hline Age of the patients & $\mathbf{3 6 - 4 4}$ yrs. & $\mathbf{4 5 - 4 9}$ yrs. & $\mathbf{5 0 - 5 4}$ yrs. & $\mathbf{5 5 - 5 9}$ yrs. & $\mathbf{6 0}-\mathbf{6 3}$ yrs. & Total \\
\hline Number of the patients & 22 & 39 & 47 & 35 & 6 & 149 \\
\hline Percentage (\%) & 14,8 & 26,2 & 31,5 & 23,5 & 4,0 & 100,0 \\
\hline
\end{tabular}

2). The analysis of the results of the treatment was conducted separately within each group. The long term results in the "ACL reconstruction on the background of gonarthrosis" group. The group of 74 patients (from 36 to 63 years). In assessing the longterm results (within 2-12 years) a progression of the joint space narrowing was marked in some of the cases. Thus, among the 58 patients without joint space narrowing before surgery, 17 (29.3\%) had progression of osteoarthritis, which is ascertained from the increase of the joint space narrowing. The long term results of the treatment on I.K.D.C. scale is shown in Figure 1. It should be noted that there were lesions of the anterior cruciate ligament graft in 8 cases (10\%). There is the link between the long term results of the treatment due to Lequesne index and the value of the medial tibial angle before surgery. The distribution of the patients according to this indicator is shown in Figure 2. Patients with the medial tibial angle of 85 and $86^{\circ}$ the worst results of the treatment due to Lequesne index.
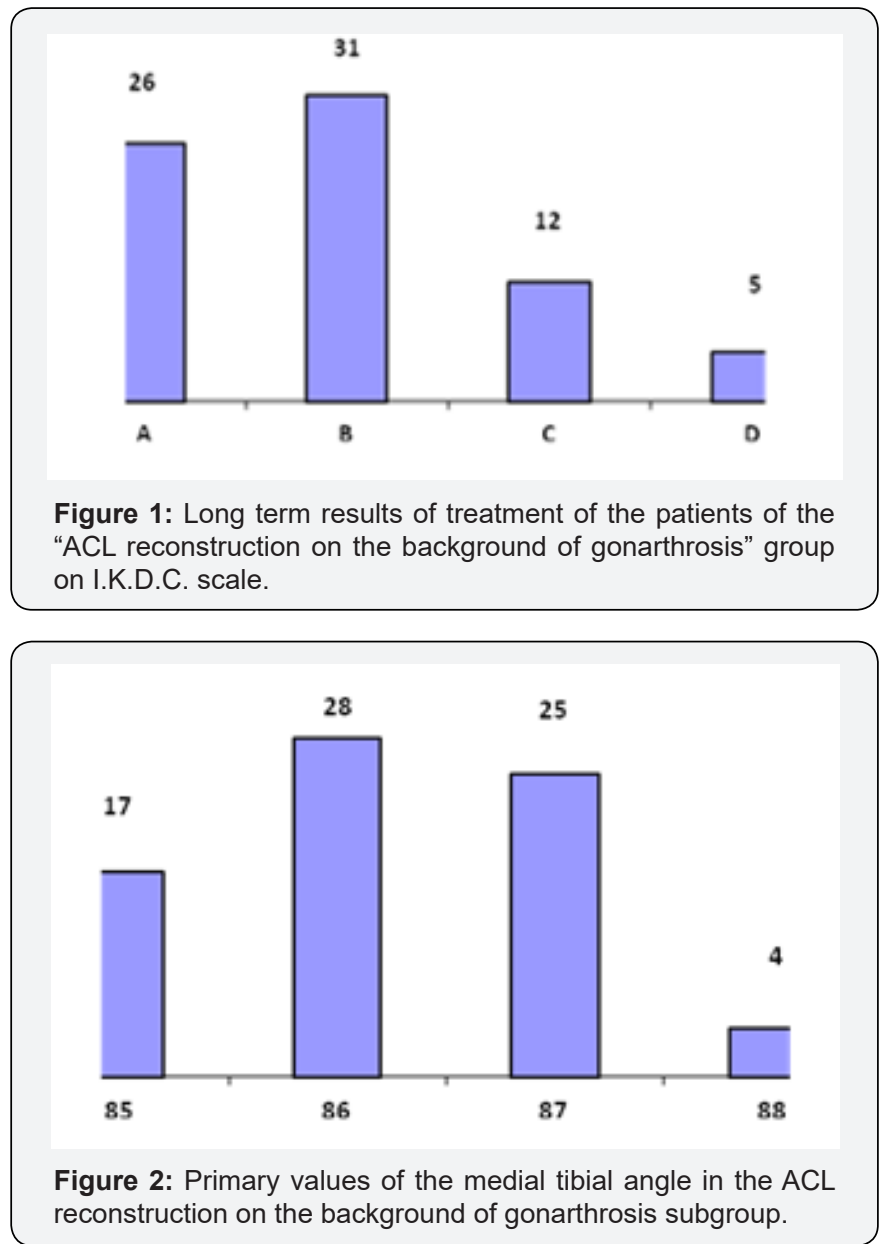
Table 2: Types of surgical interference, performed in the given group.

\begin{tabular}{|c|c|}
\hline Surgical interference & Number of patients \\
\hline ACL reconstruction on the background of gonarthrosis & 74 \\
\hline ACL reconstruction + chondroplasty & 42 \\
\hline (mosaic plasty - 6 patients, micro fracturing - 36 patients) & 21 \\
\hline ACL reconstruction + chondroplasty + high corrective tibial osteotomy (micro fracturing in all the cases) & 12 \\
\hline $\begin{array}{c}\text { High corrective tibial osteotomy with the change of the level of tibial plateau + chondroplasty (micro fracturing in all the } \\
\text { cases) }\end{array}$ & 149 \\
\hline Total & \\
\hline
\end{tabular}

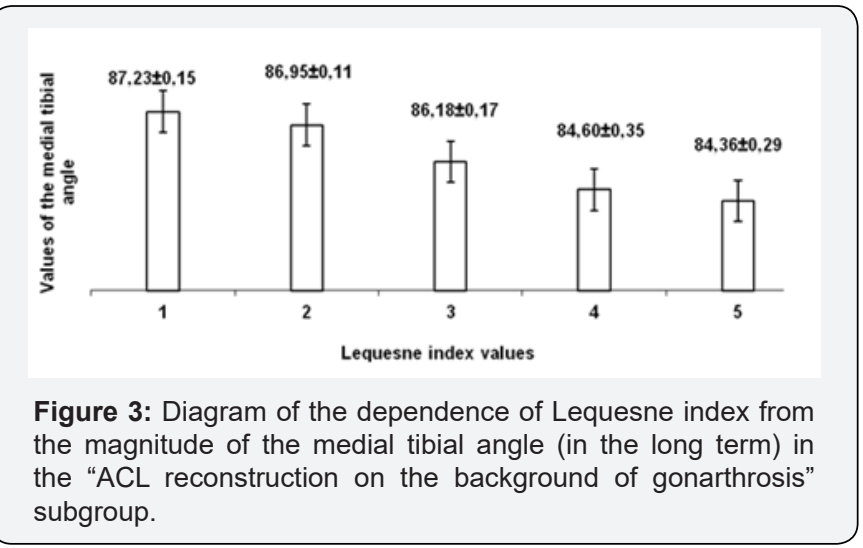

Figure 3 Diagram of the dependence of Lequesne index from the magnitude of the medial tibial angle (in the long term) in the "ACL reconstruction on the background of gonarthrosis" subgroup. Simultaneously, these groups initially had the largest proportion of cartilage lesions of the III and IV grades. All 74 patients in this subgroup had various degrees of the cartilage damage. Concerning the clinical significance, we have divided them into two groups of I-II and III-IV grades which we've divided into two subgroups due to the area of damage to $4 \mathrm{~cm}^{2}$ and more than $4 \mathrm{~cm}^{2}$. The data presented in Table 3. Dependence on the size of the cartilage of the medial tibial angle is presented in Figures $4 \& 5$. There is a clear correlation in the diagrams between the values of the medial tibial angle of $85-86^{\circ}$ and the presence of significant cartilage lesions. Thus, we can conclude that the constitutional varus deformity significantly affects the development of osteoarthritis of the knee. That is, in cases where the patient has the ACL damage on the background of medial osteoarthritis of the knee combined with a varus deformity rather difficult to expect a positive outcome of treatment.

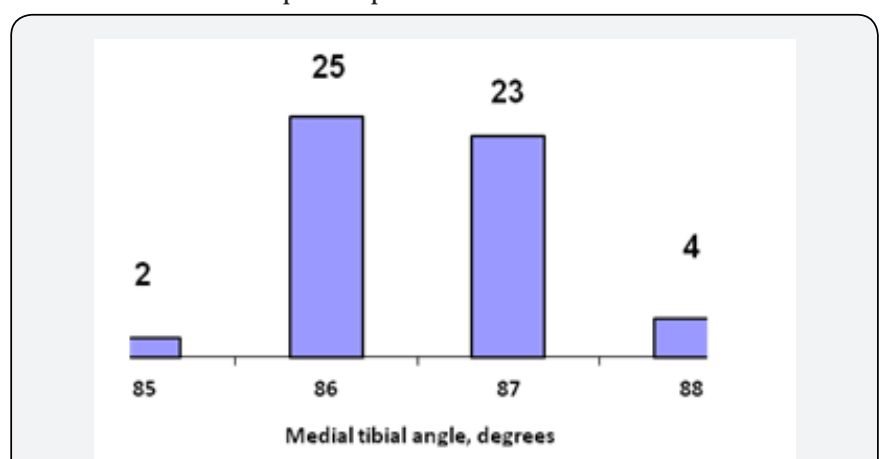

Figure 4: The values of the medial tibial angle among the patients with cartilage lesions of the I-II grades in the ACL reconstruction on the background of gonarthrosis subgroup.

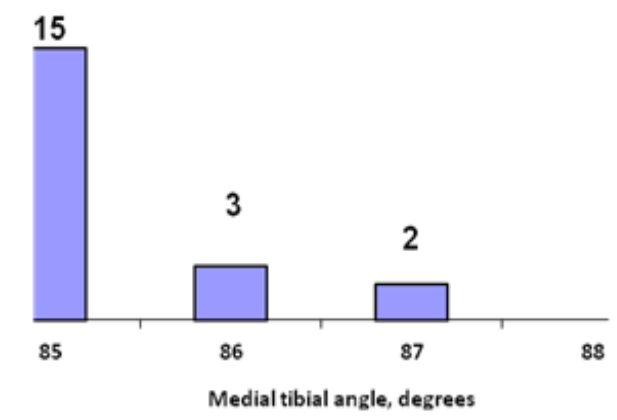

Figure 5: The values of the medial tibial angle among the patients with cartilage lesions of the III-IV grades in the ACL reconstruction on the background of gonarthrosis subgroup.

Table 3: Type of cartilage lesion in patients of the given subgroup. ACL reconstruction on the background of gonarthrosis.

\begin{tabular}{|c|c|c|c|c|}
\hline \multicolumn{2}{|c|}{$\begin{array}{c}\text { The number of patients with cartilage lesions of the I-II } \\
\text { grades }\end{array}$} & \multicolumn{2}{c|}{$\begin{array}{c}\text { The number of patients with cartilage lesions of the III-IV } \\
\text { grades }\end{array}$} \\
\hline Area & Area & Area & Area \\
\hline less than $4 \mathrm{~cm}^{2}$ & more than $4 \mathrm{~cm}^{2}$ & less than $4 \mathrm{~cm}^{2}$ & 14 & 74 \\
\hline 26 & 28 & 6 & Total $20(17,1 \%)$ & $74(100,0 \%)$ \\
\hline \multicolumn{2}{|c|}{ Total $54(72,9 \%)$} & & Than $4 \mathrm{~cm}^{2}$ \\
\hline
\end{tabular}


Long-term results in the subgroup of patients "ACL reconstruction + chondroplasty" (mosaic plastic reconstruction - 6 patients, micro fracturing - 36 patients)

A group of 42 patients, ages from 42 to 60 years. In assessing the long term results (within 2-12 years) the progression of joint space narrowing was also noted among these patients. Thus, among the 28 patients without joint space narrowing before surgery, $9(32.1 \%)$ had the progression of osteoarthritis, which is ascertained from the increase in joint space narrowing. In this treatment results did not differ much from that of the first group, where micro fracturing or mosaic plastic reconstruction were not carried (Figure 6). The form of the diagram substantially corresponds to the results of the first subgroup, which are shown in Figure 1.

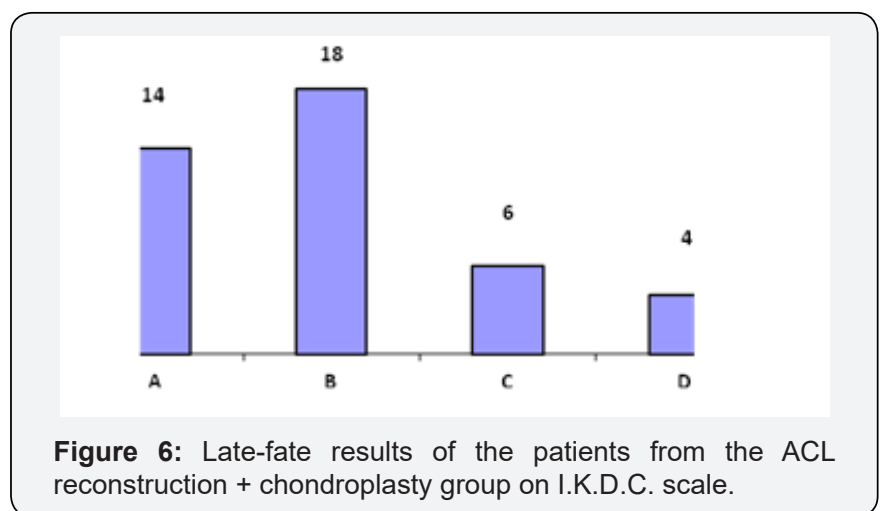

It should be noted that there were lesions of the anterior cruciate ligament graft in 4 cases (9.5\%), despite the fact that the proportion of cartilage lesions of the III-IV grades in this group were significantly higher (Table 4). The values of the medial tibial angle slightly differ from from those of the previous group
(Figure 7). It also shows the dependence of Lequesne index on the medial tibial angle value (Figure 8). However, according to the shape of the histogram, this dependence is statistically unreliable as the indicators are somewhat heterogeneous. Nevertheless, the tendency obtained in the analysis of the first subgroup, is being indirectly confirmed, and some heterogeneity of the layers, in our opinion, is due to a small number of cases (42 patients).

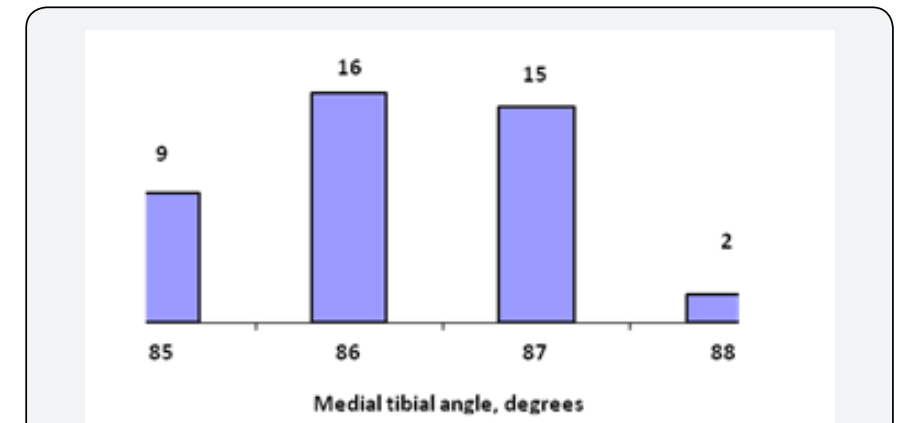

Figure 7: Original medial tibial angle values in the ACL reconstruction + chondroplasty subgroup.

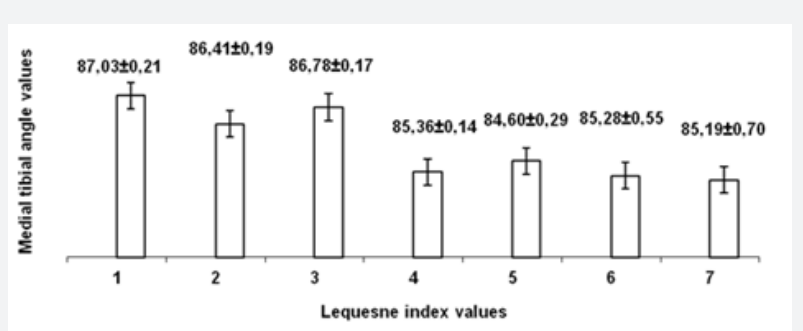

Figure 8: Diagram of the dependence of Lequesne index (in the long term) on the medial tibial angle value in the "ACL reconstruction + chondroplasty" subgroup.

Table 4: The grade of the cartilage damage in patients of the ACL reconstruction + chondroplasty» subgroup.

\begin{tabular}{|c|c|c|c|c|}
\hline $\begin{array}{c}\text { The number of the patients with cartilage damage of the } \\
\text { I-II grades }\end{array}$ & \multicolumn{2}{c|}{$\begin{array}{c}\text { The number of the patients with cartilage damage of the } \\
\text { III-IV grades }\end{array}$} \\
\hline Area & Area & Area & Area \\
\hline less than $4 \mathrm{~cm}^{2}$ & more than $4 \mathrm{~cm}^{2}$ & less than $4 \mathrm{~cm}^{2}$ & 7 & 42 \\
\hline \multicolumn{2}{|c|}{ Total $7(16,7 \%)$} & 28 & Total $35(83,3 \%)$ & $42(100,0 \%)$ \\
\hline
\end{tabular}

Aggregation of the patients with micro fracturing and mosaic plastic reconstruction into one sample is caused by numerous literature data with comparable results of these methods chondroplasty. Figure 8 Diagram of the dependence of Lequesne index (in the long term) on the medial tibial angle value in the "ACL reconstruction + chondroplasty" subgroup. The results of the treatment of the patients in the second group "ACL reconstruction + chondroplasty" confirm the fact that the reconstruction of the ACL on the background of gonarthrosis with the presence of the damage to the articular cartilage would be successful if there is no substantial constitutional varus deformity.

The results of the treatment of the patients in the "ACL reconstruction + chondroplasty + high corrective tibial osteotomy" subgroup

A group of 21 patients, age from 36 to 57 years. During the assessment of the long term results of the treatment (after 6-10 years in this subgroup) it was noted that the progression of joint space narrowing among these patients. At the time of surgery, all 
patients had joint space narrowing: I grade - 7 patients, II grade - 14 patients. In terms of assessing the long term outcomes there was a progression observed in 6 patients $(28.5 \%)$. The results of the treatment are presented in Figure 9. There were 3 cases $(14.2 \%)$ of the damage of the anterior cruciate ligament graft. It should be noted that this group had a statistically insufficient sample, so it is possible to talk only about the tendency. The main difference of this group from the others was the medial tibial angle values, which ranged from $82^{\circ}$ to $86^{\circ}$ ( $84.6^{\circ}$ on average). The level of the tibial slope ranged from 7 to $14^{\circ}$. That is, the given subgroup included patients with the varus knee cartilage injury of the medial and anterior cruciate ligament injuries. Despite the small number - 21 cases, it is still possible to compare the size and grade of cartilage damage from the previous subgroup. The nature of the cartilage injuries was not significantly different from the "ACL reconstruction + chondroplasty" subgroup (Table $5)$.

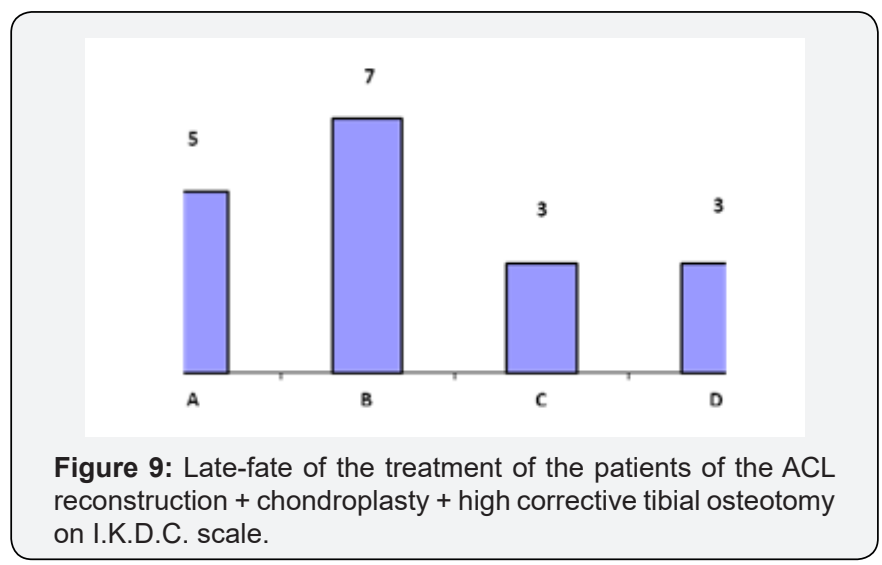

Table 5: The grade of the cartilage damage in patients of the ACL reconstruction + chondroplasty + high corrective tibial osteotomy subgroup.

\begin{tabular}{|c|c|c|c|}
\hline $\begin{array}{c}\text { The number of the patients with cartilage damage of the } \\
\text { I-II grades }\end{array}$ & \multicolumn{2}{c|}{$\begin{array}{c}\text { The number of the patients with cartilage damage of the } \\
\text { III-IV grades }\end{array}$} \\
\hline Area & Area & Area & Area \\
\hline less than $4 \mathrm{~cm}^{2}$ & more than $4 \mathrm{~cm}^{2}$ & less than $4 \mathrm{~cm}^{2}$ & 5 \\
\hline \multicolumn{2}{|c|}{ Tore than $4 \mathrm{~cm}^{2}$} \\
\hline \multicolumn{2}{|c|}{ Total $5(23,8 \%)$} & 11 & 21 \\
\hline \multicolumn{2}{|c|}{ Total $16(76,2 \%)$} & $21(100,0 \%)$ \\
\hline
\end{tabular}
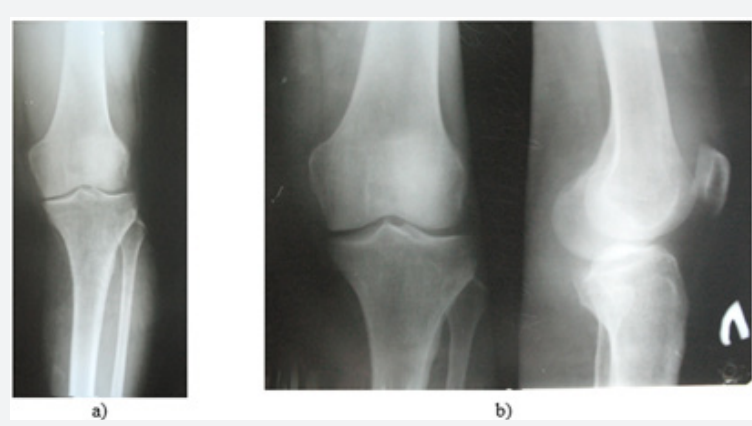

Figure 10: X-ray image of Patient L., $52 \mathrm{y} . \mathrm{o}$. before the operation: a) AP view when standing;

b) standard AP and lateral views.

A clinical example. Patient L, 52 years old, medial tibial angle of $82^{\circ}$, tibial slope of $13^{\circ}$, joint space narrowing of the II grade (Figure 10). Operated on six years ago, 6 weeks after the injury. Femoral and tibial cartilage defects were found during the revision of the knee (Figure 11). The ACL autoplastic and corrective osteotomy using the opening procedure with the correction the front axle was performed. Rating on I.K.D.C. scale - Group A. Lequesne index - 1. Radiological results are shown in (Figure 12). Clinical example. Patient F, 32 years old, medial tibial angle of $83^{\circ}$, tibial slope of $12^{\circ}$, joint space narrowing of the I grade (Figure 13). Operated on five years ago, 7 weeks after the injury. Damage of the femoral bone and tibial plateau were found during the revision of the knee cartilage (Figure 14). ACL autoplasty and corrective osteotomy using the opening procedure with the correction the front axle and a decrease in the tibial slope $\left(5^{\circ}\right)$ was performed. Rating on I.K.D.C. scale Group A. Lequesne index - 0. Radiological results are shown in (Figures 15 \& 16).

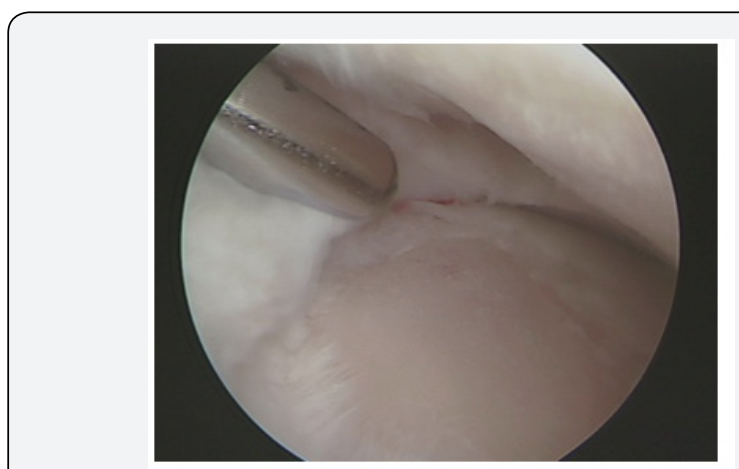

a)

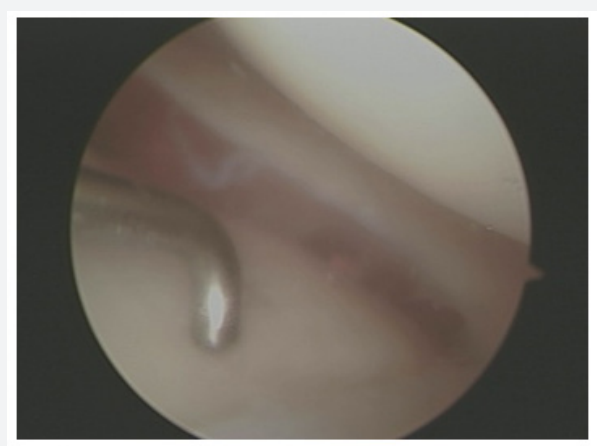

b)

Figure 11: Arthroscopic assessment of the cartilage: a) medial part; b) lateral part. 


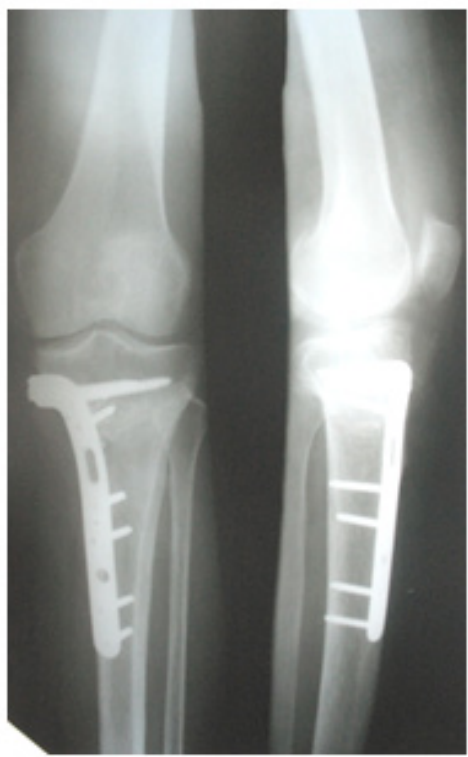

Figure 12: X-ray image (6 years after the operation).

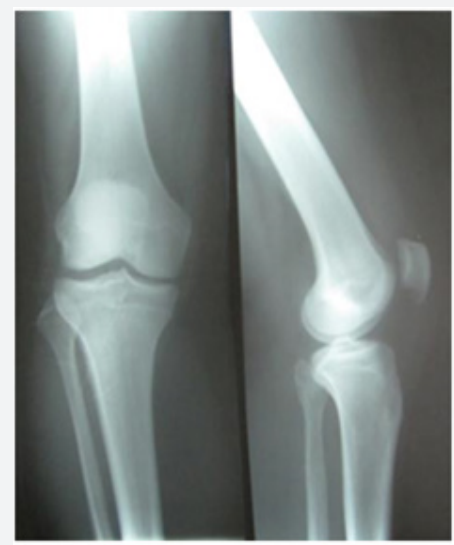

Figure 13: X-ray view of patient P, 32 y.o., before the operation.

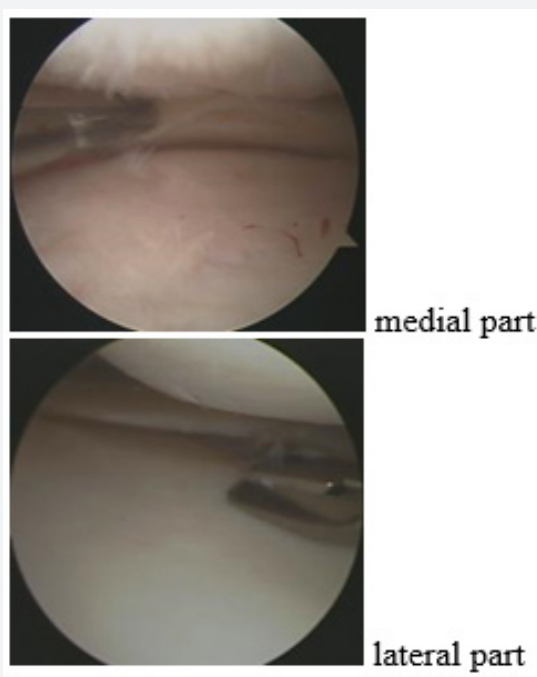

Figure 14: Arthroscopic assessment of the medial and lateral parts of patient P., 32 y.o.

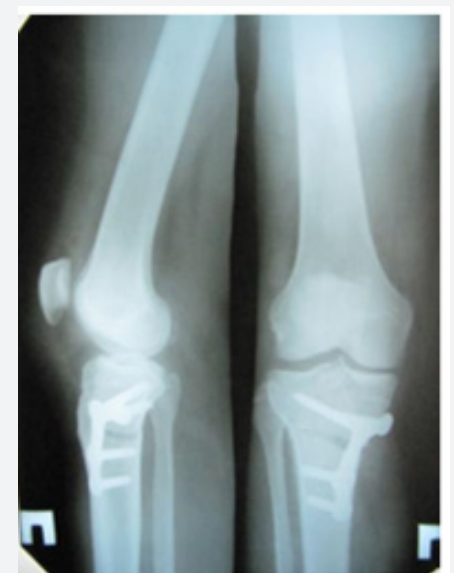

Figure 15: X-ray view of patient $P, 32$ y.o. 6 weeks after the operation.

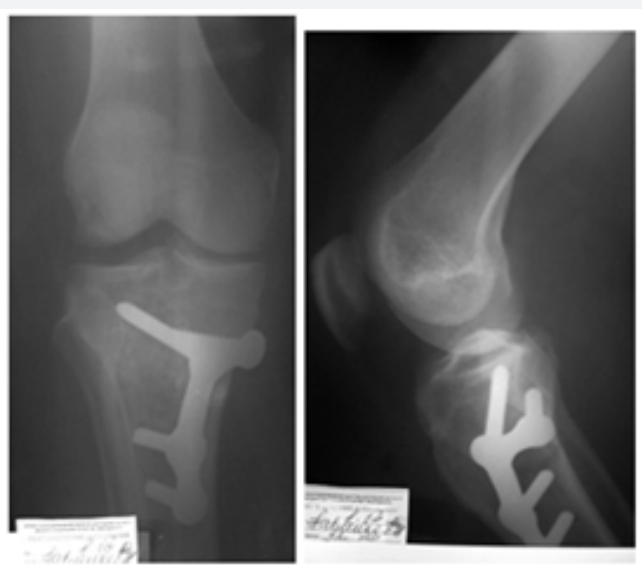

Figure 16: X-ray view of patient P., 32 y.o. 5 years after the operation.

Results of the treatment of the patients in the "High corrective tibial osteotomy with the change of the tibial slope + chondroplasty" subgroup

A group of 12 patients, age from 52 to 59 years. In assessing the long term results of the treatment (4-6 years in this subgroup) the progression of joint space narrowing among these patients was also noted. At the time of surgery, all patients had joint space narrowing: II grade -5 patients, III grade -7 patients. During the assessment of the of long term results progression observed in 3 patients (25.0\%). This group consisted of the patients with medial tibial angle values ranging from $81^{\circ}$ to $86^{\circ}\left(84,2^{\circ}\right.$ on average). The main distinguishing feature of this group was the level of the tibial plateau of $11^{\circ}$ or more. During the corrective osteotomy we reduced the level of the tibial plateau at $5-10^{\circ}$. There were the cartilage injuries of the III-IV grade with the area of more than $4 \mathrm{~cm} 2$ in all the cases. That is, this subgroup included patients with the anterior cruciate ligament injuries in combination with varus deformity of the knee, significant damage of the medial part of the cartilage and significantly greater joint space narrowing (Figures 17 \& 18). 

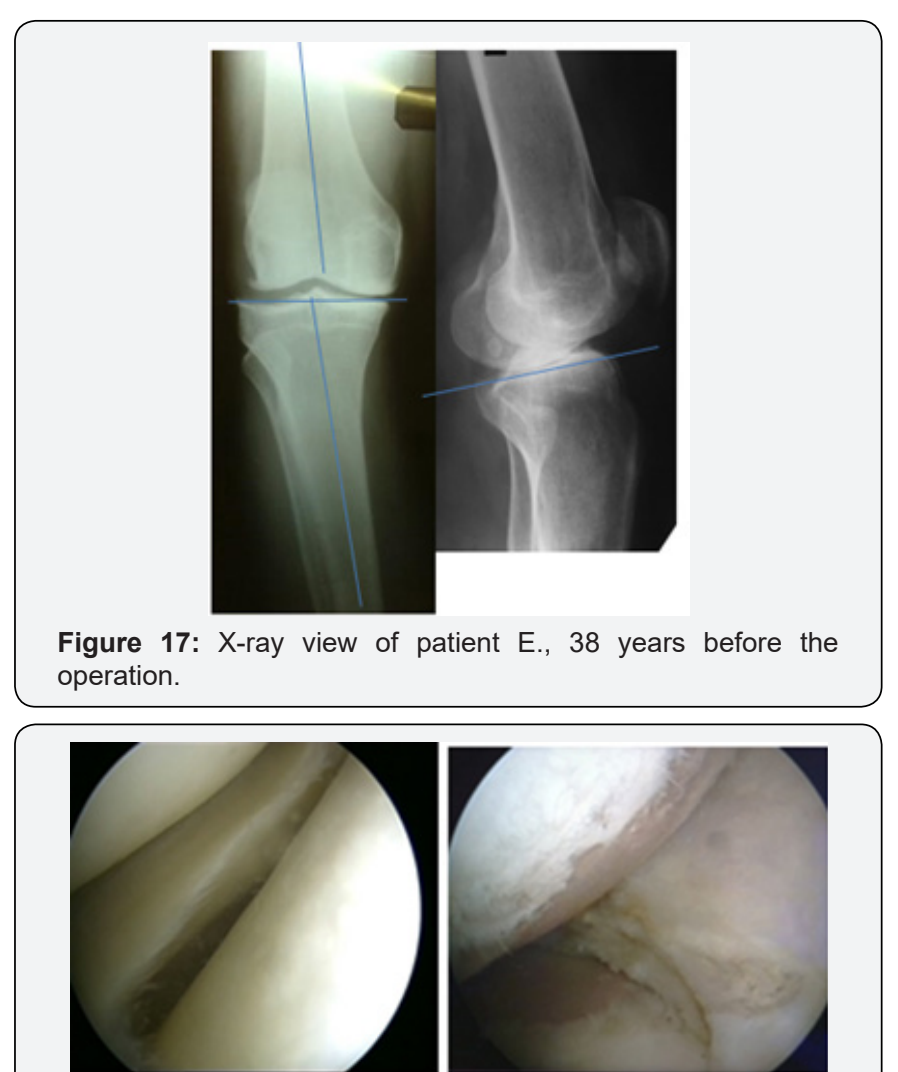

a)

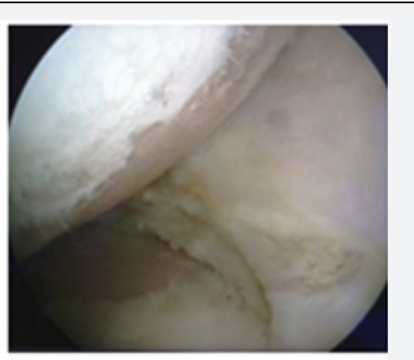

b)

Figure 18: Arthroscopic assessment of the articular cartilage: a) lateral part; b) medial part.

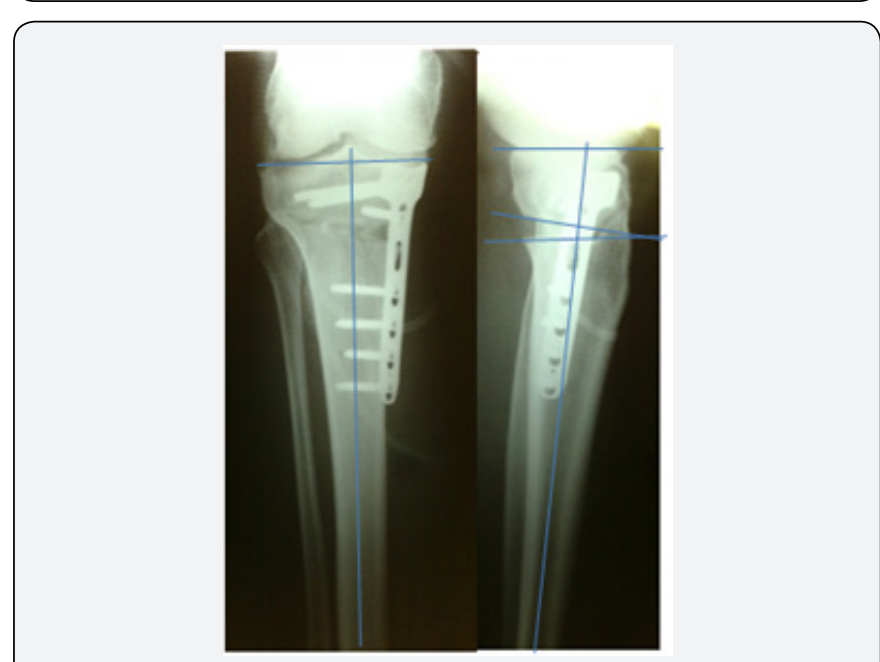

Figure 19: X-ray view after corrective osteotomy with the reconstruction.

\section{Discussion}

It should be noted that due to the number of cases of the anterior cruciate ligament reconstruction annually runs into tens of thousands [1,5,8-10]. Leading journals publish works that explore the benefits of different techniques of its reconstruction assess the benefits of different types of transplants and implants for their fixation. The share of publications dedicated to the long term results and complications remains low. So, there were 225 publications on methods of the ACL reconstruction, 19 publications on the long term results complications in the Journal of Arthroscopic and Related Surgery and "KSSTA" in 2017. Each author uses special scales for the assessment that characterize the stability and function of the knee joint, the level of physical activity and quality of life of the patients. Regardless of the combination of rating scales, the results are usually divided into "excellent", "good", "satisfactory" and "unsatisfactory". At the same time, the level of attention paid to the reasons which led to all the results other than "great" is not enough. The main reasons for the imperfect results can be divided into two groups: recurrent instability; the development of osteoarthritis of the knee. In this paper we want to analyze the causes of the second order, as the reasons of repeated injuries of the ACL are described in a great number of works. The share of the ACL transplants damage ranges from 5 to $24 \%$ and has no tendency to decrease (Figure 19).

In our opinion, a special problem group consists of the patients with the anterior or anteromedial instability on the background of chronic anterior cruciate ligament injury. A number of these patients have already started to develop posttraumatic gonarthrosis which is confirmed by arthroscopy. We are talking about patients with the first or second stage of gonarthrosis. Nevertheless, the functions of the knee joint are usually preserved, and major complaints relate precisely to the instability of the knee $[6,9,11,12]$. Thus, we have a patient with osteoarthritis of the knee with chronic anteromedial instability, complaining of the instability and pain in the medial part. The goals of treatment in such cases are:

a) To slow down the progression of osteoarthritis.

b) To restore the knee stability. There is a problem with the choice of proper treatment strategy in such situations.

Major doubts arise about the advisability of the reconstruction of the anterior cruciate ligament of the knee joint with a slowly progressing osteoarthritis $[7,9,13,14]$. Basic questions. Would not the surgery accelerate the progression of the degenerative process? Will we reach stability if we remove the pain in the knee? How to successfully reconstruct the anterior cruciate ligament on the background of developing varus deformity? In this regard, this study showed that the reconstruction of the anterior cruciate ligament on the background is possible and properly selected indications and techniques can achieve quite acceptable positive long-term results. In this case it is necessary to predict the result from two perspectives: the grade of the recurrence of the instability and the level of progression of osteoarthritis. In our sample of patients, the instability relapse rate reached $10 \%$, which is comparable with the results of the primary ACL reconstruction. The share of the progression of osteoarthritis in the long term ranged from $30 \%$ in the group with its initial manifestations and up to $50 \%$ in patients 
with significant defects of articular cartilage and joint space narrowing of the III grade (bone touches the bone).

As a result, we found out that constitutional varus deformity, which we evaluated by the medial tibial angle, significantly affects the results of the anterior cruciate ligament reconstruction in cases where the process of destruction of the articular cartilage of the medial part of the knee has already begun. With its values less than $85^{\circ}$ there was a marked progression of osteoarthritis in all the cases. In cases where patients with constitutional varus deformity had corrective osteotomy the proportion of progression of osteoarthritis was comparable with the group of patients without a varus deformity. Why did we apply the medial tibial angle indicator to assess the mechanical axis of the limb? We didn't have the opportunity to make an X-ray view of the entire limb due to the lack of the equipment. Despite the fact that this figure indirectly characterizes mechanical axis of the limb, we have often used it in such cases and got statistically significant results. A separate small group consisted of patients who have had extensive cartilage defects, a significant narrowing of the joint space in combination with large tibial slope $\left(11^{\circ}\right.$ or more). In such cases valgus osteotomy with its decrease of $7-10^{\circ}$ allowed to stabilize the knee joint and slow down the progression of osteoarthritis.

\section{Conclusion}

Based on this study, we tried to form our own tactics of choice of the surgical treatment for patients with ACL injuries on the background of osteoarthritis of the knee of the I-II grades.

i. The patient's age is very important. We rarely encountered indications in patients older than 60 years in our work. The main group consisted of patients not older than 55 years.

ii. We have not included patients with a body mass index over 30 into this group. ACL reconstruction on the background of gonarthrosis in patients with a body mass index over 30 remains the subject of debate.

iii. We did not assess the treatment results depending on the sex of the patients due to an insufficient sampling. However, there is a tendency that men have the best results.

iv. Patients under the age of 60 years, without the varus deformation damage to the articular cartilage may have the ACL reconstruction with predicted good results of the treatment. If such a patient has the articular cartilage damage of the I-IV grades area up to $4 \mathrm{~cm} 2$, it is quite possible to perform micro fracturing, mosaic plastic reconstruction or other ways the correction of this defect.

v. If the patient has varus deformity or large cartilage defects greater than $4 \mathrm{~cm} 2$, which itself leads to the formation of secondary varus is an indication for the simultaneous ACL reconstruction and high valgus tibial osteotomy. vi. In some cases, when a patient with a varus deformity and damage to the ACL has a large tibial slope ( $11^{\circ}$ and more), it is needed to consider both varus deformity correction and tibial slope reduction.

\section{Closing Remarks}

Chronic instability eventually leads to deterioration of the cartilage in the medial part. Restoring stability of the knee due to the anterior cruciate ligament reconstruction and geometry changes in the frontal and sagittal planes by valgus reconstruction and tibial slope reduction lead to a decrease in the mechanical load on the graft as well as a slower deterioration of the cartilage. It is unlikely that the anterior cruciate ligament reconstruction will enable completely to stop the cartilage from the destruction and the development of osteoarthritis, but the restoration of the stability of the knee improves the quality of life for the patients. The results of the reconstruction of the anterior cruciate ligament on the background of osteoarthritis of the knee are almost always good in the first 5-7 years, regardless of the combination of the corrective osteotomy, but in 10 years - about $25 \%$ of the patients already have indications for the prosthetics. It's hard enough to answer all the questions that arise in the course of the ACL reconstruction on the background of gonarthrosis and their number in constantly increasing. The proposed criteria also are the target of polemics. What to do if those criteria are not applicable to this very patient? Our statistics show that there is not sufficiently high probability of the positive long term results. As always, this gap is filled with personal experience of an orthopedist. ACL reconstruction on the background of gonarthrosis? Rather YES than NO.

\section{References}

1. Gifstad T, Sole A, Strand T, Uppheim G, Grøntvedt T, et al. (2013) Longterm follow-up of patellar tendon grafts or hamstring tendon grafts in endoscopic ACL reconstructions. Knee Surg Sports Traumatol Arthrosc 21(3): 576-83.

2. Leiter JRS, Gourlay R, McRae S, de Korompay N, MacDonald PB (2014) Long-term follw-up of ACL reconstruction with hamstring autograft. Knee Surg Sports Traumatol Arthrosc 22(5): 1061-1069.

3. Malahias MA, Chytas D, Nakamura K, Raoulis V, Yokota M, et al. (2018) A Narrative Review of Four Different New Techniques in Primary Anterior Cruciate Ligament Repair: "Back to the Future" or Another Trend? Sports Med Open 4(1): 37.

4. Papalia R, N Maffulli, V Denaro (2013) The Anterior Cruciate Ligament Remnant: To Leave It or Not? Arthroscopy 29(11): 1736-1737.

5. Tibor L, Chan PH, Funahashi TT, Wyatt R, Maletis GB, et al. (2016) Surgical Technique Trends in Primary ACL Reconstruction from 2007 to 2014. J Bone Joint Surg Am 98(13): 1079-1089.

6. Lind M, Lund B, Faunø P, Said S, Miller LL, et al. (2012) Medium to long-term follow-up after ACL revision. Knee Surg Sports Traumatol Arthrosc 20(1): 166-72.

7. Rambaud AJM, Semay B, Samozino P, Morin JB, Testa R, et al. (2017) Criteria for Return to Sport after Anterior Cruciate Ligament reconstruction with lower reinjury risk (CR'STAL study): protocol for a prospective observational study in France. BMJ Open 7(6): e015087. 
8. Yazdi H, A Torkaman, M Ghahramani, Moradi A, Nazarian A, et al (2017) Short term results of anterior cruciate ligament augmentation in professional and amateur athletes. J Orthop Traumatol 18(2): 171176.

9. Harris KP, Driban JB, Sitler MR, Cattano NM, Balasubramanian E, et al. (2017) Tibiofemoral Osteoarthritis After Surgical or Nonsurgical Treatment of Anterior Cruciate Ligament Rupture: A Systematic Review. J Athl Train 52(6): 507-517.

10. Nyland J, Mattocks A, Kibbe S, Kalloub A, Greene JW, et al. (2016) Anterior cruciate ligament reconstruction, rehabilitation, and return to play: 2015 update. J Sports Med 7: 21-32.

11. Hamrin Senorski E, Sundemo D, Murawski CD Alentorn-Geli E, Musahl $\mathrm{V}$, et al. (2017) No differences in subjective knee function between surgical techniques of anterior cruciate ligament reconstruction at 2-year follow-up: a cohort study from the Swedish National Knee Ligament Register. Knee Surg Sports Traumatol Arthrosc 25(12): 3945-3954.

12. Hofbauer M, Muller B, Murawski CD, Van Eck CF, Fu FH (2014) The concept of individualized anatomic anterior cruciate ligament (ACL) reconstruction. Knee Surg Sports Traumatol Arthrosc 22(5): 979-986.

13. Magnussen RA (2015) Patient-Reported Outcomes and Their Predictors at Minimum 10 Years After Anterior Cruciate Ligament Reconstruction: A Systematic Review of Prospectively Collected Data. Orthop J Sports Med 3(3): 2325967115573706.

14. Ruano JS, Sitler MR, Driban JB (2017) Prevalence of Radiographic Knee Osteoarthritis After Anterior Cruciate Ligament Reconstruction, With or Without Meniscectomy: An Evidence-Based Practice Paper. J Athl Train 52(6): 606-609.

\section{Your next submission with Juniper Publishers} will reach you the below assets

- Quality Editorial service

- Swift Peer Review

- Reprints availability

- E-prints Service

- Manuscript Podcast for convenient understanding

- Global attainment for your research

- Manuscript accessibility in different formats

( Pdf, E-pub, Full Text, Audio)

- Unceasing customer service

Track the below URL for one-step submission https://juniperpublishers.com/online-submission.php 